\title{
El uso de las TIC como paliativo de las dificultades del aprendizaje en las ciencias sociales
}

\author{
Juan Luis Fernández-Quero \\ juanluisfq@correo.ugr.es \\ Universidad de Granada
}

\begin{abstract}
Resumen
La investigación facilita y selecciona herramientas y recursos digitales TIC que se puedan aplicar para paliar las dificultades de aprendizaje en las ciencias sociales, especialmente en geografía e historia, apostando por una incentivación de las competencias digitales y tecnológicas en docentes y alumnos. De tal modo, que sirva como una consulta de referencia para la autogestión, con una recomendación específica para los pupilos. Para ello es necesario conocer al menos las principales dificultades de aprendizaje involucradas obteniendo una definición propia del concepto. Después de la revisión pertinente, se lleva a cabo una selección por criterios objetivos y por último la praxis de aquellas herramientas y recursos que obtienen las puntuaciones más altas en la discriminación final. Se atiende de una forma específica a las que están siendo promovidas por las administraciones públicas así como por las universidades, contribuyendo a su difusión. Entre otras cuestiones, se tiene en cuenta el prestigio universal, la adaptación al fin al que se requiere o los productos generados. Es evidente que el trabajo realizado posee una gran utilidad de cara a los contextos forzosos de no presencialidad, como es el caso de la pandemia generada por la COVID-19.
\end{abstract}

\section{Palabras clave}

TIC; dificultades del aprendizaje; ciencias sociales, geografía; historia. 


\title{
The use of ICT as a palliative of learning difficulties in the social sciences
}

\author{
Juan Luis Fernández-Quero \\ juanluisfq@correo.ugr.es \\ University of Granada
}

\begin{abstract}
The research facilitates and selects ICT digital tools and resources that can be applied to alleviate learning difficulties in the social sciences, especially in geography and history, betting on an incentive for digital and technological competences in teachers and students. So that it serves as a reference consultation for self-management, with a specific recommendation for pupils. For this, it is necessary to know at least the main learning difficulties involved, obtaining a definition of the concept itself. After the pertinent review, the selection makes with selection objectives criteria, and finally the praxis of those tools and resources that obtain the highest scores in the final discrimination. Those that are being promoted by public administrations as well as by universities are addressed in a specific way, contributing to their dissemination. Among other issues, taking into account universal prestige, adaptation to use or the products generated. The work carried out is very useful in the face of forced non-presence contexts caused by pandemics, such as COVID-19.
\end{abstract}

\section{Keywords}

ITC; learning difficulties; social sciences; geography; history. 


\section{Introducción, justificación y limitaciones del estudio}

Las herramientas TIC diversifican las opciones del profesorado y alumnado, especialmente útiles son las que mitigan las dificultades generadas en el modelo de transmisión y adquisición del conocimiento. La irresolución de las dificultades del aprendizaje provoca desmotivación en los estudiantes llegando algunos incluso al abandono de la materia e incentivando la generación de tópicos en ciencias sociales en disciplinas como la geografía y la historia. Existe un déficit de publicaciones que asocien TIC y dificultades de aprendizaje desde este enfoque, siendo útil para desarrollar las clases en el contexto de la no presencialidad. Las nuevas tecnologías han demostrado su valía en el proceso cuando se aplican de manera oportuna y adecuada. Sin embargo, a pesar de existir diversas herramientas y recursos, en ocasiones estos no son aplicados en las clases principalmente por desconocimiento, falta de medios en el centro y en los jóvenes o ausencia de formación por parte de los profesores. Es vital continuar promoviendo una cultura tecnológica en las aulas para conseguir una mejor adaptación de competencias al empleo por teletrabajo en un futuro, muy poco fomentado en España y transcendente para reducir el efecto económico de crisis causadas por pandemias como la generada por el coronavirus (SARS-CoV-2).

Una de las principales limitaciones albergadas al realizar la investigación proviene de la selección de los elementos tecnológicos y digitales que se adapten mejor a cada dificultad de aprendizaje dentro de la inmensidad de opciones disponibles y la especificidad que puede mostrar cada una de estas. Por esta razón, se tienen en cuenta una serie de parámetros con diferentes ponderaciones que ayudan a tal discriminación y objetividad. La consulta de fuentes, organismos oficiales, información académica contrastada y de sitios web que aportan información fiable favorece el proceso electivo. Por otra parte, mencionar que la indagación se centra en aquellas dificultades que son susceptibles de afección para todo el alumnado, pudiendo ser necesario requerir de otras herramientas y/o recursos específicos para situaciones concretas de atención a la diversidad.

\section{Hipótesis, aportaciones previas y estado de la cuestión}

Se plantea cómo hipótesis de partida la utilidad de la investigación como incentivo en puntos tan importantes y demandados por la sociedad y el sistema educativo actual como son la adquisición de competencias digitales y tecnológicas en docentes y alumnos. De manera que se consiga desarrollar a través de las tablas y esquemas una especie de guía visual intuitiva y comprensible, donde unas herramientas y recursos ayuden a hacer frente a las dificultades de aprendizaje en el contexto de la ausencia forzada de asistencia a clases. Sin olvidar de que son aplicables también para la enseñanza que ya posee una estructura orientada a la educación a distancia y online. De manera que los profesores puedan utilizar ciertas herramientas y recursos con los que contribuir a disminuir estas insuficiencias según patrones de necesidades y carencias de los alumnos, pudiendo estos también aplicarlos por sí mismos.

El Consejo europeo de Lisboa, en las conclusivas presidenciales, del 23-24 de marzo del 2000 fijó como nuevo objetivo estratégico para la Unión Europea: alcanzar la meta de ser "la economía basada en el conocimiento más competitiva y dinámica del mundo, capaz de tener un crecimiento económico sostenible con más y mejores trabajos y con una mayor cohesión social" Parlamento Europeo, 2000. Argumentaba que para lograr esto habría que adaptarse a los sistemas de educación y formación. Para ello, deberían promocionarse destrezas clave básicas, donde se incluye las Tecnologías de la Información y Comunicación (TIC) y la cultura tecnológica. En España, si bien existe un retraso respecto a otros países septentrionales europeos, desde 1985 se han aunado esfuerzos para aplicar las TIC en la educación (INTEF, 2017). Además, aparecen tales acciones incluidas por parte de las comunidades autónomas en favor del refuerzo de las TIC en la 
educación mediante legislación. A modo de ejemplo, la Ley 17/2007, de 10 de diciembre, de Educación de Andalucía o las menciones de especial importancia para desarrollar capacidades emprendedoras en el Decreto 219/2011, de 28 de junio, por el que se aprueba el Plan para el Fomento de la Cultura Emprendedora en el Sistema Educativo Público de Andalucía.

Existen estudios científicos que evidencian que las nuevas tecnologías colaboran en el proceso de Enseñanza-Aprendizaje (E-A) de la geografía e historia (Naik y Teelock, 2006; Estepa Giménez, 2009; Padilla Portillo y Gómez Zermeño, 2014; Tabor y Harrington, 2014 o más ampliamente la tesis doctoral de Seva Cañizares, 2015), aunque es cierto que son mucho más numerosos en las ciencias exactas y naturales. Después de esta extensa revisión se puede argumentar la presencia de ciertos artículos y documentos que tratan el tema de las TIC y las dificultades de aprendizaje en las ciencias sociales (geografía e historia). Algo que se ha ido incrementando con el paso de los años pero que aún debe promocionarse. Muestra de ello, es la cierta complejidad encontrada cuando se buscan documentos que relacionen a las ciencias sociales con recursos y herramientas digitales y tecnológicas, aplicadas para unas tipologías de dificultades específicas y para un periodo de formación concreto, como es la Educación Secundaria Obligatoria y Bachillerato.

Entre las publicaciones relacionadas se pueden consultar diferentes enfoques, apareciendo con más transcendencia las que apuestan por un proceso de enseñanza-aprendizaje con TIC en geografía e historia y dan ejemplos con herramientas concretas como la webquest (Acosta Barros, 2010) y uso de la cartografía, la lectura y escritura de mapas desde las TIC/TAC (Fleitas y Gómez, 2012). El modelo TPACK, cursos en línea y abiertos (MOOC) en el proceso E-A (Gómez Trigueros, 2016), la perspectiva de aprendizaje con Google Earth (Segrelles Serrano, Gómez Trigueros, 2016) o la web 2.0 y el blog (Palomo Molano, 2010). Propuestas para historia del arte (Sobrino López, 2011), la utilización de videojuegos (Irigaray y Luna, 2014; Jiménez-Palacios y Cuenca López, 2015), nuevas tecnologías en las clases de ciencias sociales (Luis de la Torre, 2005) y las infraestructuras de datos espaciales (Álvarez Otero y Lázaro y Torres, 2019). De una manera más amplia también aparecen más trabajos (Sánchez Cabielles, 2014 o Seva Cañizares, 2015). El siguiente grupo atiende a aquellos que critican el modelo de enseñanza de la geografía actual por uno con una digitalización específica con una adecuada utilización de las TIC (Marrero Urbín, 2012 y Royo Climent, 2017). Sin olvidar, las que se centran exclusivamente en el profesorado respecto a la temática (Vera Muñoz y Pérez y Pérez, 2004; Arancibia Herrera y Badia Garganté, 2015).

En cuanto a las dificultades de aprendizaje aparece Liceras $(1997,2000)$ y Liceras et Romero (2016) refiriéndose concretamente a las dificultades de aprendizaje de las ciencias sociales y cómo tratarlas. Es observable como algunas de estas se repiten en varias publicaciones siendo en ocasiones destacadas por los propios autores; véase por ejemplo a García Perales y García Perales, 2003, García de la Vega, 2007 y Fernández Verdú et al, 2017. Respecto a su evolución en geografía sean contrastado publicaciones relevantes históricamente y otras más actuales observándose su progresividad, a los ya mencionados se añaden Sandford (1972), Graves (1985), Rickey y Bein (1996), Liceras (1997), Benejam y Pagés (1997), Gurevich (1998) o Comes (1998). Estos coinciden con los más actuales como Santiago Rivera (2006) aclarando la problemática que supone la comprensión de la complejidad espacial y cambiante, Claval (2007) en torno a la epistemología y conceptos o García Ruiz y Jiménez López (2006). En cambio, existe una visión diferente de similitud de tales manuscritos cuando sí se mencionan las dificultades de aprendizaje relacionadas con la aplicación de las nuevas tecnologías en la geografía (Fleitas y Gómez, 2012). En la materia de historia se pueden observar investigaciones a lo largo del tiempo con Asensio, Carretero, Pozo (1986), Pluckrose (1993), Salazar Sotelo (2001), Cózar Mata (2009), Valls y Facal (2012), Kitson et al (2015), Liceras y Romero (2016), Fernández Verdú et al (2017) y por último se puede citar a Prats (2017). 
Prueba de la demanda y la necesidad de este tipo de formación son los postgrados que se están desarrollando en torno a esta cuestión con una creciente expansión. DEP Institut (Consultado: 18/04/2020. Disponible: https://www.educaweb.com/masters-oficiales-de/tecnologia-educativa)

\section{Metodología}

Para interpretar las aportaciones previas y el estado de la cuestión se ha seguido un procedimiento exhaustivo, donde ha sido consultada la legislación y diversas fuentes científicas y otros materiales procedentes de las administraciones públicas, intentando dar siempre prioridad en el proceso de búsqueda y elección a aquellas revistas más contrastadas. Las bases de datos principales utilizadas han sido Web of Science, Scopus y Google Académico, donde se han consultado la gran mayoría de las revistas vinculadas a la temática en relación al factor de impacto JCR (Education \& researchSSCI). Sin obviar, los materiales didácticos de la Universidad de Granada y cursos asociados a la Universidad de La Rioja, entre otros. Se han utilizado fuentes de recopilación como Índices CSIC y revistas específicas para cada aspecto, al igual que un índice de revistas proporcionado por la AGE. A lo que hay incorporar la inserción de palabras clave, que posteriormente se tienen en cuenta sobre todo en revistas de alto impacto con los "hot topics", los artículos más descargados y citados en los últimos años.

El procedimiento de consulta ha seguido los siguientes pasos:

- Es realizada una búsqueda en Web of Science y Scopus con los siguientes conceptos en primer y segunda estancia para concretar la información: "geografía", "historia", "TIC*", "dificultades de aprendizaje", "ciencias sociales", "enseñanzas", "CCSS", "educación secundaria", "tecnología". Términos que también se escribieron en inglés.

- En la segunda fase, se opta por hacer una indagación por revistas afines al foco de la investigación en la JCR acotado por la categoría (Education \& research) siendo todas las consultadas de carácter internacional con clara preferencia por los artículos de acceso en abierto: Research and Practice in Technology Enhanced Learning, Computers \& education, Learning and instructions, Journal of Teacher Education, Journal of Computer Assisted Learning, Learning Media and Technology, IEEE Transactions on Learning Technologies, Journal of Educational Technology \& Society, ETR \& D-Educational Technology Research Development y Journal of Educational Computing Research. En cada una de ellas, es llevado a cabo un proceso que aunque puede tener ciertos matices individualizados se centra en visualizar los artículos más citados en su conjunto, los más descargados en los últimos 90 días y los más citados desde 2017 (aunque hay algunas donde se ha hecho desde 2013), a lo que se añade la utilización de las palabras clave anteriores sin acotaciones de tiempo.

- El tercer paso se centra en una búsqueda de fuentes de recopilación bibliográfica como Índices CSIC y otras revistas específicas de geografía e historia a través del listado ofrecido por la Asociación de Geógrafos Españoles (AGE) y específicamente en la sección WOS denominada Journal of Art \& Design Education. Las revistas que más información ofrecen al respecto son las siguientes y con las búsquedas mostradas: Didáctica de la Geografía ("dificultades de aprendizaje", "tecnología" "tecnología educativa", "geografía" e "historia", "TIC" "ESO" y "dificultades de aprendizaje"). Journal of Geoscience Education ("K-7", hasta "K-12", más éxito la K-7, K-8 y K-12), The Geography Teacher ("K-7", hasta "K-12", learning difficulties). Revistas de Educación Ambiental como Environmental Education Research, International Research in Geographical and Environmental Education, Journal of Environmental Education y Applied Environmental Education and Communication con 
distintas formaciones de búsqueda ("High school Classroom", "ITC", "geography" e "history"). Geoenseñanza ("TIC" "enseñanza"), Didácticas específicas ("geografía" e "historia ESO"), Journal of Geography ("learning difficulties", "geography", "ITC", "geography", "history") e International Journal of Art \& Design Education ("learning difficulties geography ITC" "learning difficulties of geography ITC" "learning difficulties geography ITC" "learning of difficulties history ITC").

- El cuarto, pesquisa concreta en Google Académico y por palabras clave e indagación en el buscador de Google: "Dificultades de aprendizaje TIC ciencias sociales"; "Dificultades de aprendizaje" AND "TIC ciencias sociales". "Dificultades de aprendizaje TIC historia secundaria"; "Dificultades de aprendizaje" AND "TIC" AND "historia secundaria". "Dificultades de aprendizaje TIC geografía secundaria"; "Dificultades de aprendizaje" AND "TIC" AND "geografía secundaria".

- Quinto y último paso, consulta de materiales didácticos de la universidad de Granada correspondientes a Morales Rodríguez, Navarro Valverde y Valiñas López (2018) en relación a los Complementos a la Formación de las Ciencias Sociales y la innovación docente del profesorado. Para finalizar, se obtiene información de los cursos virtuales online de la Universidad de La Rioja (La Web 2.0 recursos educativos y Competencia digital para docentes).

Por otro parte, se ha indagado en la información que ofrecen lugares webs, fuentes científicas como tesis doctorales o artículos que contrastan los medios necesarios a utilizar contra las dificultades y la propia experiencia en el uso de estas herramientas y recursos para comprobar su eficiencia. Para distinguir las que van a contribuir a combatir las dificultades de aprendizaje se ha utilizado una selección por criterios inscribiendo sólo aquellas que satisfacen mejor tales especificaciones. A disposición de los profesores y alumnos se han puesto desde bases de datos, editores de distinto tipo, plataformas, webs, portales, blogs, presentaciones hasta simuladores virtuales, entre otras cuestiones.

\section{Las dificultades del aprendizaje en ciencias sociales, geografía e historia}

Las definiciones de dificultades de aprendizaje han evolucionado con el tiempo encontrándose ciertamente incompletas en algunos casos o con falta de consenso. Incluso unas de las referencias más utilizadas como la APA presenta carencias normalizadas del término (American Psychiatric Association, 2002. En: Figueiredo, Mazera, Guillaumon Emmela, Fernández Alba, 2014). En este sentido, se ha apostado por una significación propia que es adaptada a la parte más universal del concepto y a la vez especifica en las ciencias sociales: Incidencia de aspectos extrínsecos e intrínsecos que afectan al proceso de enseñanza-aprendizaje intentando entorpecer la consecución de competencias que tiene que alcanzar el alumnado en las materias de ciencias sociales. En cuanto a la revisión bibliográfica realizada se ha seguido el mismo procedimiento que el propuesto en la metodología para llevar a cabo la fundamentación contextual y teórica pero aplicada a cada tipología de dificultad de aprendizaje. A continuación se muestran los resultados de la revisión realizada en referencia a las dificultades de aprendizaje.

En las ciencias sociales incorporar las asociadas al aprendizaje memorístico, repetitivo, poco significativo y nada comprensivo y muy especialmente la relacionada con los conceptos; ya sea por ser erróneos, complejos, abstractos o con falta de consenso. También se añaden más dificultades de aprendizaje referentes a los esquemas cognitivos previos, los tópicos, las relacionadas con el tiempo, las derivadas de la práctica de la evaluación, las relacionadas con el planteamiento interdisciplinar, entre otras que pueden guardar relación con las anteriores. En contraposición, 
puede surgir un paradigma adverso y es que las TIC implantadas además de aminorar los efectos de tales problemáticas también en ciertas ocasiones crean unas dificultades propias derivadas de su uso.

\section{a. Específicas de la disciplina de geografía}

Las dificultades más asiduas a la geografía que se han encontrado giran en torno a acepciones como la comprensión del espacio, lectura, comprensión e interpretación de mapas y planos, conceptos geográficos, observación en geografía, actitudes y por último valores en el proceso de toma de decisiones sobre el uso del espacio y gestión medioambiental. Entre estas prevalecen la compresión del espacio, los conceptos geográficos y la lectura, interpretación y comprensión de mapas y planos (Esquema 1).

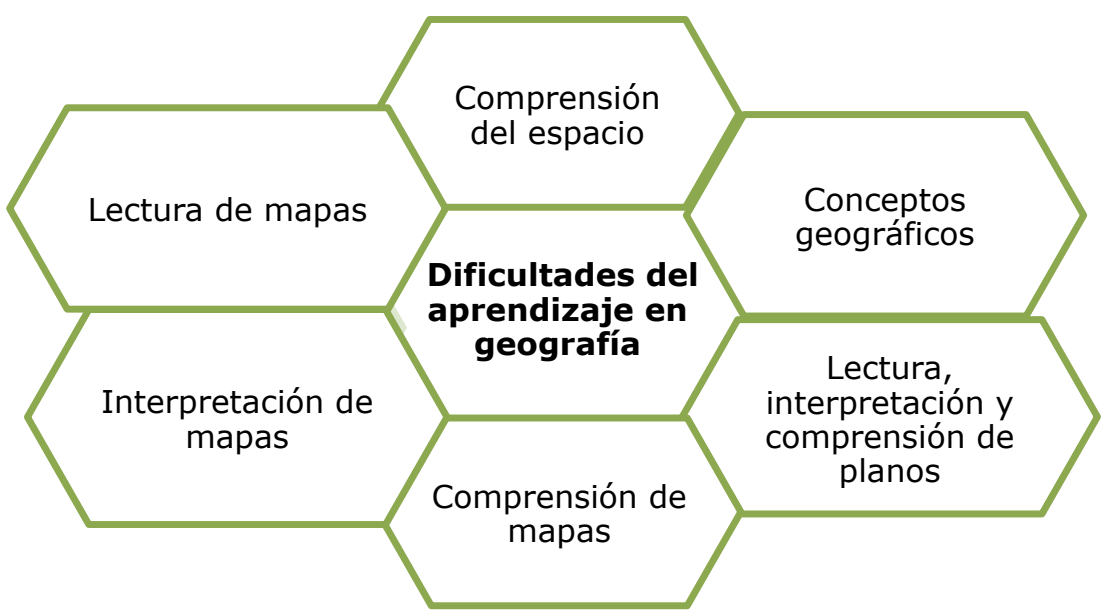

Esquema 1. Predominancia de las dificultades de aprendizaje en geografía tras el proceso revisor Elaboración propia.

Una vez efectuada esta explicación es momento de introducirse en las referentes a la historia, que tan estrechamente relacionada esta con la geografía, es por eso que cuesta a veces disociar ciertas dificultades pues ambas materias pueden compartirlas. Aun así, aparecen algunas que ciertamente poseen una identidad o se asocian más a una u otra especialidad.

\section{b. Específicas de la disciplina de historia}

Las más extendidas entre los alumnos son la naturaleza epistemológica de la historia y la comprensión conceptual junto a la interpretación y comprensión de los hechos y acontecimientos, el contexto espacio temporal y la diferencia de opiniones y hechos. A lo que se une en cierto modo el tema de la causalidad y multi-causalidad (Esquema 2). 


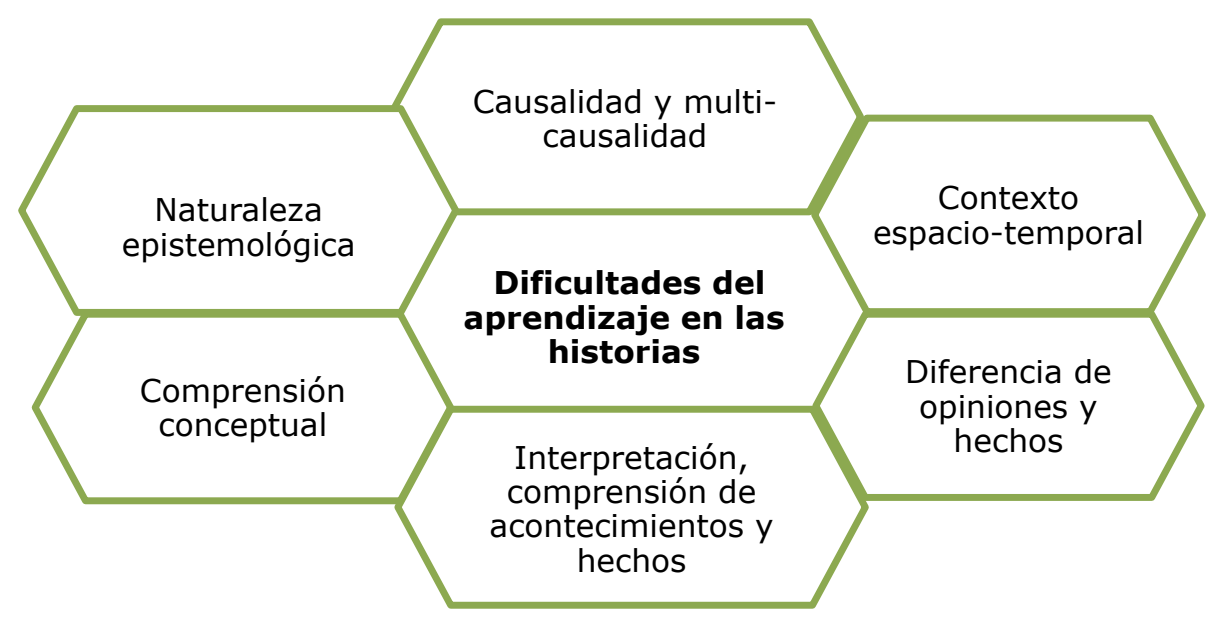

Esquema 2. Predominancia de las dificultades de aprendizaje en las historias tras el proceso revisor Elaboración propia.

Una vez descrito este apartado se acaba el cuarto enunciado del documento, ahora ya es posible abordar el tema de las TIC con la afección y misión de atenuar las dificultades de aprendizaje expuestas.

\section{Las herramientas TIC y digitales como atenuantes versus las dificultades del aprendizaje}

Para distinguir las herramientas TIC y digitales que van a combatir las dificultades del aprendizaje se han consultado aquellas que mediante una selección por criterios han obtenido una adecuación mayor. Todos ellos tienen el mismo valor de ponderación con una máxima puntuación de 6 . Además para verificar la realidad de las cualidades y posibilidades que según sus creadores y críticos poseen se han contrastado tales anunciaciones mediante la experiencia propia. La especificación es la siguiente:

Prestigio por usuarios y popularidad (provincial o menor, regional, nacional, internacional: 0,25 por ítems superado), sus funcionalidades, capacidades (específica, múltiples, excepcionales: 0,33 por ítems, el último nivel 0.34), curva de aprendizaje (lenta, media, lenta-media para comprenderlas todas pero rápida para las funciones básicas fundamentales requeridas, rápida: 0.25 por ítems superado), capacidad para generar productos (Ej. Duración de grabación en material audiovisual, calidad, variedad, etc; baja, media, alta, muy alta: 0.25 por ítems superado). La posibilidad de poseer al menos una versión gratuita (versión de pago a bajo costo, gratuita; 0.5 por ítems superado) y su adaptación al fin para el que se requiere (baja, media, alta; 0,33 por ítems, el último nivel 0.34). La puntación mostrada en las representaciones refleja este orden (Tabla 1, 2, 3 y 4):

Tras la detallada revisión científica realizada se ha observado que los autores suelen atribuir al campo de las ciencias sociales las siguientes determinaciones:

a.1). Abstracción y complejidad de conceptos, falta de interés por los conocimientos y asignaturas, aprendizaje memorístico y causalidad múltiple.

Son tratables por medio de la gamificación y videotutoriales, se ha demostrado que estos mejoran la adquisición y entendimiento de ciertas dificultades (Contreras Espinosa y Eguia, 2017) abandonando la memorización excesiva y poco significativa. Permiten poner ejemplos de causalidad múltiple y combatirla. En el caso de los videos cuando son interactivos son capaces de 
mejorar la interdisciplinariedad en el aprendizaje (Smithwick, Baxter, Kim, Edel-Malizia, Rocco, Blackstock, 2018). A continuación, se muestran los 4 mejores elementos encontrados para ello y su justificación minuciosa tras una argumentación de sus posibilidades (Tabla 1):

\begin{tabular}{|c|c|}
\hline \multicolumn{2}{|r|}{ Principales elementos seleccionados versus a.1). } \\
\hline $\begin{array}{l}\text { Herramienta } \\
\qquad \mathrm{s}\end{array}$ & Justificación \\
\hline \multirow[t]{3}{*}{ Kahoot } & Gamificación para preparar conceptos por medio de preguntas \\
\hline & $\begin{array}{l}\text { Aspectos clave: Prestigio, permite combinar diapositivas y es considerado un } \\
\text { referente en la temática }\end{array}$ \\
\hline & Puntaje: $1+0,66+1+1+1+1=5,66$ \\
\hline \multirow{5}{*}{$\begin{array}{l}\text { OBS Studio, } \\
\text { Zoom }\end{array}$} & Grabaciones de video con múltiples posibilidades \\
\hline & $\begin{array}{l}\text { OBS Studio. Aspectos clave: Muy completo en versión gratuita, adaptación a } \\
\text { varios sistemas operativos }\end{array}$ \\
\hline & Puntaje: $1+1+0,75+1+1+1=5,75$ \\
\hline & $\begin{array}{l}\text { Zoom. Aspectos clave: Comparte presentaciones, con las últimas actualizaciones } \\
\text { parece ir resolviendo sus agujeros de seguridad iniciales }\end{array}$ \\
\hline & Puntaje: $1+0,66+1+0,75+1+1=5,41$ \\
\hline \multirow[t]{3}{*}{ Skype } & Realización de videoconferencias \\
\hline & $\begin{array}{l}\text { Aspectos clave: Larga duración de las videollamadas y la capacidad de grabación } \\
\text { y de participantes en versión gratuita, superando en esta situación a Google Meet }\end{array}$ \\
\hline & Puntaje: $1+0,66+1+0,75+1+1=5,41$ \\
\hline \multirow{5}{*}{$\begin{array}{l}\text { Prezi y } \\
\text { Genially }\end{array}$} & Presentaciones \\
\hline & Prezi. Aspectos clave: Calidad, prestigio y popularidad \\
\hline & Puntaje: $1+0,66+1+0,75+1+1=5,41$ \\
\hline & $\begin{array}{l}\text { Genially. Aspectos clave: Excelentes funcionalidades, plantillas, es interactivo, } \\
\text { permite animación y la acción de la gamificación, integra las posibilidades de } \\
\text { distintas apps y prestigio }\end{array}$ \\
\hline & Puntaje: $1+1+1+1+1+1=6$ \\
\hline
\end{tabular}

Tabla 1. Herramientas seleccionadas para combatir las dificultades del aprendizaje a.1) en ciencias sociales

Elaboración propia.

a.2). La transferencia de conocimiento interdisciplinar, la naturaleza del conocimiento social (epistemología), las ideas previas erróneas, esquemas cognitivos previos y tópicos. La asimilación de procedimientos, las dificultades relacionadas con el tiempo, las subyacentes de la práctica de evaluación y las generadas por las propias TIC.

En el caso de la transferencia de conocimientos entre disciplinas es muy recomendable asociar las materias para hacer trabajos colaborativos entre alumnos. Algo fundamental en el mercado de trabajo y que no suele ser realizado en los centros por docentes de distintas disciplinas, entre otras cuestiones, por la carga extra que supone el procedimiento. En tal perspectiva, es prácticamente imprescindible agregar un sitio en la web o en la nube donde se pueda editar el trabajo 
conjuntamente facilitando el proceso para los alumnos. De este modo, al tratar el tema de la epistemología social, los tópicos y las ideas previas concebidas desde el punto de vista de las TIC, la mejor forma de hacerlo es promulgando los ejemplos de su aplicación científica y su contribución para resolver problemas de la sociedad actual. Para la evaluación de los procedimientos se pueden utilizar las rubricas y la Evaluación Basada en Proyectos o la flipped classroom que permiten reflejar mejor el aprendizaje del alumno. Además según sus resultados es posible observar si los procedimientos que hemos utilizado en la enseñanza han sido lo suficientemente satisfactorios. Las cuestiones relacionadas con el tiempo son aplicables a medios más específicos como líneas del tiempo. Las generadas por las TIC se pueden reconducir según Fernández-Quero (2020) mediante una inmersión progresiva y la aplicación del modelo TPACK, algo que varía entre otros aspectos por el contexto y las herramientas utilizadas. En la siguiente representación (Tabla 2) se señalan las que alcanzan en la investigación las puntuaciones más elevadas para luchar contra tales dificultades:

\begin{tabular}{|c|c|}
\hline \multicolumn{2}{|r|}{ Principales elementos seleccionados versus a.2). } \\
\hline Herramientas & Justificación \\
\hline \multicolumn{2}{|r|}{ Edición colaborativa y suplemento de estudio } \\
\hline $\begin{array}{l}\text { Google Drive } \\
\text { Google Classroom }\end{array}$ & $\begin{array}{l}\text { Puntaje: } 1+0,66+1+0,75+1+1=5,41 \\
\text { Puntaje: } 1+1+1+1+1+1=6\end{array}$ \\
\hline \multicolumn{2}{|c|}{ Interacción con la realidad científica de las ciencias sociales } \\
\hline $\begin{array}{l}\text { Google Scholar } \\
\text { Scopus } \\
\text { Web of Science } \\
\text { Dialnet } \\
\text { Índices CSIC }\end{array}$ & $\begin{array}{l}\text { Puntaje: } 1+0,66+1+0,75+1+1=5,41 \\
\text { Puntaje: } 1+1+0,75+1+1+0,66=5,41 \\
\text { Puntaje: } 1+1+0,75+1+1+0,66=5,41 \\
\text { Puntaje: } 1+0,66+1+0,75+1+1=5,41 \\
\text { Puntaje: } 0,75+0,66+1+0,75+1+1=5,16\end{array}$ \\
\hline \multicolumn{2}{|c|}{ Rúbricas, Aprendizaje Basado en Proyectos (ABP) y flipped classroom } \\
\hline $\begin{array}{l}\text { Idoceo } \\
\text { Plantilla ABP Canvas } \\
\text { Trello } \\
\text { Quiztlet } \\
\text { Edpuzzle flipped }\end{array}$ & $\begin{array}{l}\text { Puntaje: } 1+1+1+1+0,5+1=5,5 \\
\text { Puntaje: } 1+0,33+1+1+1+1=5,33 \\
\text { Puntaje: } 1+0,66+1+0,75+1+1=5,41 \\
\text { Puntaje: } 1+0,66+1+0,75+1+1=5,41 \\
\text { Puntaje: } 1+0,66+1+0,75+1+1=5,41\end{array}$ \\
\hline \multicolumn{2}{|r|}{ Creadores de líneas del tiempo } \\
\hline Timeline & Puntaje: $1+0.33+1+0,75+1+1=5,08$ \\
\hline
\end{tabular}

Tabla 2. Herramientas seleccionadas para combatir las dificultades del aprendizaje a.2) en ciencias sociales Elaboración propia.

\section{Propios del proceso de enseñanza-aprendizaje en geografía}

Para la geografía e historia se utiliza el mismo procedimiento de evaluación. Con la intención de combatir las dificultades de aprendizaje en geografía son tomadas ciertas herramientas en el proceso que en muchos casos están siendo innovadoras en las aulas y que tienen un enorme potencial. Se suelen presentar aquellas asociadas a los SIG, los videos participativos y explicativos con una utilidad interdisciplinar, de mejora de sistemas socio-ecológicos para los conceptos abstractos y lectura, explicación y comprensión de mapas (Royo Climent, 2017; Smithwick, Baxter, Kim, Edel-Malizia, Rocco, Blackstock, 2018) y las presentaciones digitales (eleva el entendimiento por el procedimiento de segmentación de diapositivas expuesto por: Mayer, Howarth, Kaplan, Hanna, 2017). Con las herramientas SIG se pueden conseguir bajo una buena terapia pedagógica 
muchos beneficios asociados como: mejorar la comprensión del espacio, la lectura, interpretación y comprensión de mapas, los conceptos geográficos, la observación en geografía, las actitudes y el proceso de toma de decisiones en el territorio, además de la gestión medioambiental. Para ello, estas herramientas a veces se sirven de la visión de la web 2.0 y también de plataformas donde colgar e interaccionar con videos pudiendo utilizar también las mencionadas anteriormente (Tabla 3):

\begin{tabular}{|c|c|}
\hline \multicolumn{2}{|c|}{ Principales elementos seleccionados en geografía } \\
\hline Herramientas & Justificación \\
\hline \multicolumn{2}{|c|}{ Generación de datos } \\
\hline Infraestructura de Datos Espaciales de España (IDEE) & Puntaje: $0,75+1+0,75+1+1+1=5,5$ \\
\hline \multicolumn{2}{|c|}{ Producción cartográfica } \\
\hline $\begin{array}{l}\text { Google maps } \\
\text { Google Earth } \\
\text { Cartociudad } \\
\text { National Geographic Map Maker } \\
\text { ARGIS online escolar } \\
\text { Instituto Geográfico Nacional } \\
\text { Rediam }\end{array}$ & $\begin{array}{l}\text { Puntaje: } 1+1+1+0,75+1+1=5,75 \\
\text { Puntaje: } 1+1+0,75+1+1+1=5,75 \\
\text { Puntaje: } 0,75+0,66+1+0,75+1+1=5,1 \\
6 \\
\text { Puntaje: } 1+0,66+1+1+1+1=5,66 \\
\text { Puntaje: } 1+1+1+1+1+1=6 \\
\text { Puntaje: } 0,75+1+1+1+1+1=5,75 \\
\text { Puntaje: } 0,5+1+1+1+1+1=5,5\end{array}$ \\
\hline \multicolumn{2}{|c|}{ Editor y creador de videos } \\
\hline Filmora & Puntaje: $1+1+1+1+1+1=6$ \\
\hline \multicolumn{2}{|c|}{ Editar, subir y visualizar contenido audiovisual } \\
\hline $\begin{array}{l}\text { Youtube } \\
\text { Vimeo }\end{array}$ & $\begin{array}{l}\text { Puntaje: } 1+0,66+1+1+1+1=5,66 \\
\text { Puntaje: } 1+0,66+1+0,75+1+1=5,41\end{array}$ \\
\hline
\end{tabular}

Tabla 3. Herramientas seleccionadas para combatir las dificultades del aprendizaje en geografía Elaboración propia.

\section{Propios del proceso de enseñanza-aprendizaje en las historias}

La problemática que acontece al déficit producido en el proceso de E-A en materias como la historia y la historia del arte se hace frente en lo correspondiente a las TIC en distintas formas según la cuestión a tratar. Son muchas las herramientas a utilizar y en ciertos contextos se pueden combinar entre dificultades y materias afines. La gamificación (Rivero, 2011; Irigaray y Luna, 2014) y la realidad aumentada (Sobrino López, 2011) junto a los simuladores de ambientes (especialmente visitas virtuales) y las audioguías son muy útiles en las disciplinas de historia actuando en favor de una mejor valoración que consigue aumentar el interés de los alumnos incrementándoles la empatía por su aprendizaje. Además, se plantea la situación de positividad que pueden provocar como complementos a ciertos contenidos ceñidos por el tema de las capacidades cognitivas por la edad. El material donde ampliar conocimientos, como las distintas bases de datos bibliográficas, enciclopedias y diccionarios digitales específicos en línea, ayudan no sólo a distinguir los conceptos sino también a comprender la epistemología de esta ciencia. La lectura y edición de ebooks favorece al docente programar ejercicios en virtud de una información falsa que el adolescente tiene que transformar por medio de fuentes fiables, ayudando a contrastar en cierta medida la representación previa histórica de la situación que pueda tener el alumno, esta faceta investigadora se promueve mediante el ABP. El contraste de hechos y opiniones se trabaja e implementa de una forma efectiva con webquest por los profesores innovadores (Hernández Cardona, 2011 y Rivero, 2011). 
Desde el punto de vista de la comprensión conceptual ayudan mucho los videos explicativos (Arancibia y Badia, 2013) y las presentaciones que incorporan imágenes, mapas y gráficos. Además de tales audiovisuales, el cine (Acosta Barros, 2010) y los cazatesoros (Hernández Cardona, 2011; Rivero, 2011) son utilizados para ayudar a comprender los acontecimientos históricos, contextuales y espaciales. A su vez, todos los materiales que puedan prestar un carácter explicativo didáctico, como los videotutoriales, pueden complementar una cierta carencia de didáctica por parte de algunos profesores en primacía de los contenidos académicos. Por su parte, son cada vez más los docentes en historia que utilizan wikis y especialmente los blogs, algo que ponen de manifiesto profesores de historia y geografía como María Elena González Párraga, con 10 años de experiencia, pro-TIC y varios traslados realizados. A esta visión del blog se une también la tesis de Seva Cañizares (2015). Estos proceden además como repositorios de material innovando los procedimientos instaurados de enseñanza y hasta tratan con un manejo didáctico adecuado el tema de la causalidad y multi-causalidad, junto a los instrumentos antes mencionados. En definitiva, se trata de que cada profesional y alumnos elijan, combinen y pongan en práctica tales conocimientos para intentar hacer frente a las problemáticas que van surgiendo para seguir avanzando en este contexto. La selección es la siguiente (Tabla 4):

\begin{tabular}{|c|c|}
\hline \multicolumn{2}{|c|}{ Principales elementos seleccionados en las historias } \\
\hline Herramientas & Justificación \\
\hline $\begin{array}{l}\text { 1) Cospaces, } \\
\text { 2) 3d Warehouse, } \\
\text { 3) ARCore, } \\
\text { 4) Minecraft Education Edition, } \\
\text { 5) Tinytap, } \\
\text { 6) Classdojo, } \\
\text { 7) Audacity }\end{array}$ & $\begin{array}{l}\text { Realidad aumentada, 3D y audioguía. Puntaje: } \\
\text { 1) y 2) } 1+0,66+0,75+0,75+1+1=5,16 \\
\text { 3) } 1+1+0,75+1+1+0,66=5,41 \\
\text { 4) } 1+1+0,75+0,75+0,5+1=5 \\
\text { 5) } 1+1+1+0,75+1+0,33=5,08 \\
\text { 6) } 1+0,66+1+0,75+1+0,66=5,07 \\
\text { 7) } 1+0,66+1+1+1+1=5,66\end{array}$ \\
\hline $\begin{array}{l}\text { 8) Europeana, } \\
\text { 9) Google Arts \& Culture }\end{array}$ & $\begin{array}{l}\text { Contenedores de información. Puntaje: } \\
\text { 8) } 1+0,66+1+0,75+1+1=5,41 \\
\text { 9) } 1+0,66+1+1+1+1=5,66\end{array}$ \\
\hline $\begin{array}{l}\text { 10) Diccionario Bibliográfico de la Real } \\
\text { Academia de Historia "RBE" , 11) Gran } \\
\text { Enciclopedia de España Online, 12) Gran } \\
\text { Enciclopedia Iberoamericana, 13) Oxford } \\
\text { Reference Online Premium, } \\
\text { 14) Oxford Art Online }\end{array}$ & $\begin{array}{l}\text { Enciclopedias y diccionarios en línea. Puntaje: } \\
\text { 10) } 0,75+0,66+1+1+1+1=5,41 \\
\text { 11) } 0,75+0,33+1+1+1+1=5,08 \\
\text { 12) a 14) } 1+0,33+1+1+1+1=5,33\end{array}$ \\
\hline $\begin{array}{l}\text { 15) Censo-Guía de Archivos de España e } \\
\text { Iberoamérica, } \\
\text { 16) Web Museo del Prado }\end{array}$ & $\begin{array}{l}\text { Bases de datos bibliográficas y simuladores de } \\
\text { ambientes. Puntaje: } \\
\text { 15) } 1+0,66+1+1+1+1=5,66 \\
\text { 16) } 1+1+1+1+1+1=6\end{array}$ \\
\hline $\begin{array}{l}\text { 17) Fbreader, 18) Openoffice.Org Writer, } \\
\text { 19) Wix, 20) Weebly, 21) Creately, 22) } \\
\text { Google Sites, 23) G. C. (1,2,3 tu caza en } \\
\text { la red) }\end{array}$ & $\begin{array}{l}\text { Lectura y edición de ebooks, cazatesoros, wikis } \\
\text { y páginas webs. Puntaje: } \\
\text { 17) a 22) } 1+0,66+1+0,75+1+1=5,41 \\
\text { 23) } 1+0,33+1+0,75+1+1=5,08\end{array}$ \\
\hline $\begin{array}{l}\text { 24) Screencast-O-Matic, } \\
\text { 25) Canvas, } \\
\text { 26) Proyecto Cine y Educación }\end{array}$ & $\begin{array}{l}\text { Editores de video y comprensión a través del } \\
\text { cine. Puntaje: } \\
\text { 24) } 1+0,66+1+1+1+1=5,66 \\
\text { 25) } 1+0,66+1+0,75+1+1=5,41 \\
\text { 26) } 0,75+1+1+0,75+1+1=5,5\end{array}$ \\
\hline
\end{tabular}


27) Moodle,

28) Blogger,

29) Wordpress
Blogs. Puntaje:

27) $1+0,66+1+1+1+1=5,66$

28) $1+0,66+1+0,75+1+1=5,41$

29) $1+1+0,75+1+0,5+1=5,25$

Tabla 4. Herramientas seleccionadas para combatir las dificultades del aprendizaje en la historia Elaboración propia.

Una vez finalizado este trance, toca exponer las capacidades de información y de utilidad que ofrecen ciertos organismos en el contexto actual de crisis para afrontar la educación con las TIC en el confinamiento acontecido.

\section{Principales medios, recursos y enlaces web en el contexto de la no presencialidad}

A las anteriores herramientas hay que añadir recursos fundamentales derivados de las administraciones públicas competentes y que sin duda son una base primordial. De tal forma que en esta situación provocada por la COVID-19 tanto los profesores como los alumnos deben al menos poseer una clara referencia a nivel nacional y otra que puede derivar de la comunidad autónoma, en este caso se atiende a Andalucía (Tabla 5):

Principales recursos educativos recopilados en promoción por la administración pública en la situación derivada de la covid-19 aplicables a la geografía e historias

\begin{tabular}{|c|c|}
\hline \multicolumn{2}{|r|}{ Nacional } \\
\hline INTEF & https://intef.es/ \\
\hline \multicolumn{2}{|c|}{ Propuestos para Educación Secundaria y Bachillerato } \\
\hline Procomún & http://procomun.educalab.es/es \\
\hline Proyecto EDIA & https://cedec.intef.es/recursos/; https://exelearning.net/ \\
\hline eTwinning & https://www.etwinning.net/es/pub/index.htm \\
\hline Proyecto EDAD & http://recursostic.educacion.es/secundaria/edad/ \\
\hline $\begin{array}{l}\text { Observatorio de } \\
\text { Tecnología Educativa }\end{array}$ & $\begin{array}{l}\text { https://intef.es/tecnologia-educativa/observatorio-de- } \\
\text { tecnologia-educativa/ }\end{array}$ \\
\hline $\begin{array}{l}\text { Experiencias } \\
\text { Educativas } \\
\text { Innovadoras }\end{array}$ & $\begin{array}{l}\text { https://intef.es/recursos-educativos/experiencias-educativas- } \\
\text { inspiradoras/ }\end{array}$ \\
\hline $\begin{array}{l}\text { La aventura de } \\
\text { aprender }\end{array}$ & $\begin{array}{l}\text { https://intef.es/recursos-educativos/la-aventura-de- } \\
\text { aprender/ }\end{array}$ \\
\hline $\begin{array}{l}\text { Banco de imágenes y } \\
\text { sonidos }\end{array}$ & http://recursostic.educacion.es/bancoimagenes/web/ \\
\hline Aula virtual del INTEF & http://formacion.intef.es/tutorizados/ \\
\hline Banco de rúbricas & $\begin{array}{l}\text { https://cedec.intef.es/banco-de-rubricas-y-otros- } \\
\text { documentos/ }\end{array}$ \\
\hline Formación Profesional & \\
\hline
\end{tabular}




\begin{tabular}{|c|l|}
\hline $\begin{array}{l}\text { Simuladores de } \\
\text { Formación Profesional }\end{array}$ & $\begin{array}{l}\text { http://recursostic.educacion.es/fprofesional/simuladores/ } \\
\text { web/ }\end{array}$ \\
\hline Todo FP & $\underline{\text { http://www.todofp.es/inicio.html }}$ \\
\hline Rincón del profesor & $\underline{\text { https://europa.eu/learning-corner/\#item_1 }}$ \\
\hline Escuela de Adultos & $\underline{\text { http://www.aulamentor.es/ }}$ \\
\hline Aula mentor & CCAA de Andalucía \\
\hline \multicolumn{2}{|c|}{\begin{tabular}{l} 
Averroes (Agrega) \\
https://blogsaverroes.juntadeandalucia.es/eaprendizaje/; \\
\hline http:/agrega.juntadeandalucia.es/
\end{tabular}} \\
\hline
\end{tabular}

Tabla 5. Recursos educativos recomendados por la administración en el contexto de la no presencialidad Elaboración propia.

El Instituto Nacional de Tecnologías Educativas y de Formación del Profesorado (INTEF) es una referencia principal en la situación actual siendo derivada del Ministerio de Educación y Formación Profesional. A partir de su involucración y acceso en diferentes proyectos es posible acceder a gran variedad de recursos, donde también se especifican para la formación profesional y la escuela de adultos. En Andalucía predomina la referencia de la Junta al portal Averroes siendo muy valiosos los contenidos procedentes del proyecto Agrega.

Existen otros muchos recursos que pueden ayudar a superar las dificultades de aprendizaje en el contexto actual, pero es conveniente que al menos sean recomendados por instituciones y organismos oficiales antes de ponerlos en práctica, dando más seguridad a los alumnos y docentes. Por su parte, la Universidad de La Rioja (UNIR, 2019) y profesores de la Universidad de Granada (Morales Rodríguez, Navarro Valverde y Valiñas López, 2018) se han aventurado a difundir recursos con la intención de fortalecer las competencias TIC y la resiliencia a las problemáticas actuales de los alumnos y a los presentes y futuros profesores. De entre todos los recursos verificados se han seleccionado algunos de ellos atendiendo a los criterios de: formación más completa (variedad, cantidad, calidad y transcendencia: hasta 2 puntos, 0,5 por ítems), popularidad y reconocimiento de la comunidad educativa (provincial o menor, regional, nacional, internacional: hasta 2 puntos, 0,5 por ítems) y adecuación a las materias (temática afín, posibilidad de aplicación y utilidad: hasta 2 puntos, 1 primer ítems, 0,5 los posteriores).

Queda por tanto una puntuación máxima alcanzada de 6 puntos de acuerdo con la discriminación realizada (Tabla 6 ):

Otros recursos educativos recopilados por criterios de selección aplicados a la geografía e historias (covid-19)

\begin{tabular}{|c|c|}
\hline $\begin{array}{c}\text { Todos los derivados de las } \\
\text { herramientas del capítulo V }\end{array}$ & IGN, ArcGIS online, etc. \\
\hline \multicolumn{1}{|c|}{ Temáticas } & \multicolumn{1}{c|}{ Enlaces y puntajes } \\
\hline Documentales & \\
\hline $\begin{array}{c}\text { Planeta Documental, } \\
\text { documental RTVE }\end{array}$ & $\begin{array}{l}\text { https://www.planetadocumental.com/; } ; 1,5+1,5+2=5 \\
\text { https://www.rtve.es/; } 1,75+1,5+2=5,25\end{array}$ \\
\hline Editoriales & \\
\hline
\end{tabular}




\begin{tabular}{|c|c|}
\hline $\begin{array}{l}\text { Aula planeta, } \\
\text { Anaya, } \\
\text { Santillana, } \\
\text { Vicens vives }\end{array}$ & $\begin{array}{l}\text { https://www.aulaplaneta.com/; } 2+2+1,75=5,75 \\
\text { www.anayaeducacion.es/; } 2+2+1,75=5,75 \\
\text { https://santillana.es/; } 2+2+1,75=5,75 \\
\text { http://www.vicensvives.com/; } 2+2+1,75=5,75\end{array}$ \\
\hline \multicolumn{2}{|l|}{ Webs y enlaces } \\
\hline $\begin{array}{l}\text { Recursos educativos } \\
\text { de la AGE }\end{array}$ & $\frac{\text { https://www.age-geografia.es/site/recursos-didacticos/; }}{2+1,5+2=5,5}$ \\
\hline REA & http://www.historiayarqueologia.com/; $2+1,5+2=5,5$ \\
\hline Histodidáctica & http://www.ub.edu/histodidactica/; $1,75+1,5+2=5,25$ \\
\hline $\begin{array}{l}\text { Cidead (Recursos TIC } \\
\text { Educación) }\end{array}$ & $\frac{\text { http: } / / \text { recursostic.educacion.es/secundaria/edad/; }}{2+1,5+2=5,5}$ \\
\hline $\begin{array}{l}\text { Web de Ma Auxiliadora } \\
\text { de la Torre Cadenas }\end{array}$ & $\frac{\text { https://flautarociera.com/ccss/?page_id }=363}{2+1+2=5}$ \\
\hline $\begin{array}{l}\text { Museo Metropolitano } \\
\text { de Arte de Nueva York }\end{array}$ & $\begin{array}{l}\text { https://www.metmuseum.org/art/metpublications/titles-with- } \\
\text { full-text-online?searchtype=F; } 1,75+2+1,5=5,25\end{array}$ \\
\hline \multicolumn{2}{|l|}{ Blogs } \\
\hline Profesor Francisco & https://www.profesorfrancisco.es/; $2+1,5+2=5,5$ \\
\hline $\begin{array}{l}\text { Webs y blogs de Rosa } \\
\text { Liarte }\end{array}$ & $\begin{array}{l}\text { https://rosaliarte.com/; } 2+1,5+2=5,5 \\
\text { https://leccionesdehistoria.com/; } 2+1,5+2=5,5\end{array}$ \\
\hline
\end{tabular}

Tabla 6. Otros recursos educativos recopilados por evaluación con criterios aplicados a la geografía e historia en el contexto de la no presencialidad

Elaboración propia.

Una vez terminada esta fase, es momento de concretar los resultados de la investigación prosiguiendo con una discusión que culminará en un cierre conclusivo.

\section{Resultados}

El trabajo contiene una visión generalizada y completa de asociación de las dificultades del aprendizaje más recurrentes respecto a las TIC en las ciencias sociales, geografía e historia. Por ello, la investigación realizada en este documento posee un aporte a lo que generalmente se venía realizando hasta el momento. Por otra parte, se ha conseguido encontrar y comprobar herramientas y recursos mencionados que por sus características pueden ayudar a combatir la plasmación de las dificultades de aprendizaje bajo una adecuación pedagógica y de conocimiento acertada. La elaboración propia de tablas y esquemas ha sido necesaria para plasmar visualmente los avances que se iban desarrollando. A lo que hay que incorporar una definición propia del término dificultades del aprendizaje, que es adaptada a la parte más universal del concepto y a la vez concreta de las ciencias sociales. El número de herramientas (aunque a veces se pueden implementar y combinar) seleccionado para hacer oposición a tales dificultades en este trabajo ha sido mayor en la historia que en la geografía, siendo siempre menor en su especificidad en relación a la historia del arte.

Los instrumentos ofrecidos al profesor en las revistas y trabajos científicos son mayores que las investigaciones referentes a materiales que puedan satisfacer las necesidades educativas de los alumnos de una manera autónoma. Es recomendable que estos utilicen o se familiaricen al menos 
con los denominados (Tabla 7) INTEF y Agrega, Google Académico, Dialnet y Índices-CSIC, además de herramientas de creación de presentaciones innovadoras como Prezzi o Genially y de edición colaborativa como Google Drive. Plataformas de videos como YouTube o Vimeo y editores de video sencillos como Screencast-O-Matic o Filmora. Además, en geografía la utilización de Google Earth y ciertos recursos provenientes de ArcGIS y el IGN. Ejemplo: Glosario de términos geográficos para las pruebas de acceso a la universidad (IGN, 18/09/2020. Disponible en: https://www.ign.es/ web/ ign/portal/recursos-educativos/glosario-IGN-AGE). En historia aprender sobre algunas de las fuentes de recopilación bibliográfica para buscar información al respecto ofrecidas en las tablas y los simuladores de la realidad como el del Museo del Prado.

Elementos mínimos aconsejables a utilizar por el alumno para facilitar y progresar en su proceso de Enseñanza-Aprendizaje

\begin{tabular}{|c|c|c|}
\hline \multicolumn{3}{|c|}{ Desde un punto de vista general } \\
\hline $\begin{array}{l}\text { Consulta de } \\
\text { información }\end{array}$ & $\begin{array}{l}\text { Google scholar, } \\
\text { Índices-CSIC y Dialnet }\end{array}$ & $\begin{array}{l}\text { https://scholar.google.es/schhp?hl=es; } \\
\text { https://indices.csic.es/; https:// } \\
\text { dialnet.unirioja.es/ }\end{array}$ \\
\hline $\begin{array}{l}\text { Web de interés de las } \\
\text { administraciones }\end{array}$ & $\begin{array}{l}\text { INTEF, Agrega } \\
\text { (Averroes) }\end{array}$ & $\begin{array}{ll}\text { https: / / intef.es } / ; & \text { http: }: / /\end{array}$ \\
\hline Presentaciones & Prezzi y Genially & $\begin{array}{l}\text { https://prezi.com/; https://www.genial.ly/ } \\
\underline{\text { es }}\end{array}$ \\
\hline Edición colaborativa & $\begin{array}{l}\text { Google drive (a través } \\
\text { de cuenta Google) }\end{array}$ & https://www.google.com/ \\
\hline Plataformas de video & YouTube y Vimeo & $\begin{array}{l}\text { https://www.youtube.com/; } \\
\underline{\text { https://vimeo.com/es }}\end{array}$ \\
\hline Editores de video & $\begin{array}{l}\text { Screencast-o-matic ó } \\
\text { Filmora }\end{array}$ & $\begin{array}{l}\text { https://screencast-o-matic.com/; } \\
\text { https://filmora.wondershare.com/es/ }\end{array}$ \\
\hline \multicolumn{3}{|c|}{ Geografía } \\
\hline $\begin{array}{l}\text { Visualizadores de } \\
\text { mapas y contenidos } \\
\text { afines a la educación }\end{array}$ & $\begin{array}{l}\text { Google Earth, ArcGIS } \\
\text { (Esri) e IGN }\end{array}$ & $\begin{array}{l}\text { https://www.google.com/intl/es/earth/ } \\
\text { https://colegios.esri.es/portal-recursos/; } \\
\text { https://www.ign.es/web/ign/portal }\end{array}$ \\
\hline \multicolumn{3}{|c|}{ Historia } \\
\hline $\begin{array}{l}\text { Bases de datos, } \\
\text { contenedores de } \\
\text { información }\end{array}$ & $\begin{array}{l}\text { Elementos comprendi- } \\
\text { dos entre Europeana y } \\
\text { Censo-guía de Archi- } \\
\text { vos de España e Ibero- } \\
\text { américa (Tabla 4) }\end{array}$ & $\begin{array}{l}\text { https://www.europeana.eu/es; } \\
\text { https://artsandculture.google.com/; } \\
\text { http://dbe.rah.es/ ; } \text { https:// } \\
\text { gee.mienciclo.com/; } \\
\text { https://www.oxfordreference.com/; https:// } \\
\text { www.oxfordartonline.com/; } \\
\text { http://censoarchivos.mcu.es/ }\end{array}$ \\
\hline Simuladores virtuales & Museo del Prado & https://www.museodelprado.es/ \\
\hline
\end{tabular}

Tabla 7. Elementos que al menos debería utilizar el aprendiz para favorecer y avanzar en su proceso de Enseñanza-Aprendizaje

Elaboración propia.

También ha sido posible recopilar los más destacados recursos digitales que las administraciones públicas han promulgado a disposición de la comunidad educativa a nivel nacional y en el contexto andaluz. Por último, mencionar la transcendencia y utilidad del contenido del artículo científico por la importancia que posee en el contexto (COVID-19) proporcionando instrumentos a los profesores 
y alumnos que les puedan servir de ayuda tanto para la situación de pandemia como para otros contextos educativos similares.

\section{Discusión}

Una acción polémica puede ser la distinción entre herramientas y recursos, que entre los propios artículos y materiales consultados en la investigación no queda clara. Desde este punto de vista, se han considerado principalmente recursos aquellos que proceden de las propias herramientas señaladas en el capítulo $V$, los documentales, editoriales, webs y enlaces específicos, blogs y los descendientes del INTEF, Averroes y sus derivados. Los recursos y herramientas plasmadas, además de estar contrastados han sido puestos a prueba por el autor con la intención de observar su adecuación a la materia y sus funcionalidades in situ, donde se ha comprobado verdaderamente las capacidades o posibilidades que poseen, aunque previamente ya se había indagado en comparaciones. Los problemas más comunes en los softwares se encuentran en las funcionalidades de pago o incompatibilidad entre sistemas (Windows, Mac y Linux principalmente), algo que ha sido apreciado en tal elección.

Se han añadido algunos instrumentos de pago como es el caso de ciertas editoriales, aunque estos servicios deberían ser ofrecidos por los centros, al menos en aquellos públicos por la incidencia de alumnos desfavorecidos que reciben. Tal y como pone de manifiesto el estudio de Murillo y Martínez-Garrido (2018) donde prácticamente el 90\% de los estudiantes que contienen son de esta índole, con su correspondiente brecha digital. Existe un debate abierto en torno al menor número de interés de las investigaciones científicas respecto a la situación de la historia del arte en la Educación Secundaria Obligatoria y Bachillerato. No sólo desde su aplicación con TIC respecto a la historia sino en la no consideración como materia propia hasta el bachillerato y su optatividad (Real Decreto 1105/2014, de 26 de diciembre, por el que se establece el currículo básico de la Educación Secundaria Obligatoria y del Bachillerato). Algo que sin duda influye en la cuestión presentada. No obstante, los recursos obtenidos a través de elementos como museos y aulas virtuales del arte hacen posible una cierta paliación de estas carencias desde el punto de vista de las TIC con algunos recursos de mucha calidad.

En cuanto al tema de atención a la diversidad es posible una aplicación de tales elementos en la lucha contra tal paliación. Sin embargo, en el caso de las Necesidades Educativas Especiales (NEE) requieren ser acompañadas de unas tecnologías específicas que permitan crear oposición a problemas psíquicos, funcionales o motores. Como se puede comprobar se han cumplido las expectativas de la investigación y de su hipótesis inicial donde se esperaban encontrar herramientas y recursos digitales que se pudieran implementar por alumnos y profesores. También su representación de una manera ordenada y visualmente expositiva a las dificultades de aprendizaje de las ciencias sociales y de tales materias específicas (geografía e historia) junto a su asociación a las TIC.

\section{Conclusiones}

El documento trata un campo de investigación importante en el contexto actual y sirve como guía de consulta tanto por parte del profesorado como del alumnado con abundante información visual y gráfica. Al recopilar los recursos clave que las instituciones públicas están fomentando en esta crisis pandémica, de una forma expositiva y precisa, se está colaborando con estas en la difusión de elementos que facilitan las clases en el panorama de ausencia presencial. Por otra parte, la 
mención del medio que se vincula a una herramienta específica con la consecuente contrastación científica permite un mayor entendimiento y apertura de investigaciones propias según la conformidad de cada lector (Ejemplo: Dificultad asociada: Prejuicios de la historia memorística, empatía a la disciplina. Medio: la gamificación (Rivero, 2011). Herramienta propuesta: ArCore. Acción del lector: Búsqueda de otras herramientas o recursos seleccionados similares mediante subjetividad). El trabajo realizado ha permitido conocer las dificultades del aprendizaje, desde un punto de vista general en las ciencias sociales y propias de las disciplinas de geografía y la historia como se manifiesta en el apartado correspondiente (capítulo IV). La colaboración en la mitigación de las dificultades (capítulo V-VII), el fomento de las nuevas tecnologías que prácticamente está presente en todo el documento y la selección de recursos digitales y herramientas TIC (capítulo VVII), mostrándose todo sintetizado en un formato visual atractivo.

En un futuro a próximo y medio plazo va a surgir una apuesta más decisiva por las TIC y la digitalización en el proceso E-A debido sobre todo a la situación actual para incrementar el nivel de resiliencia ante nuevas situaciones similares que puedan presentarse. Sin embargo, es muy probable que la creación de herramientas TIC específicas para paliar unas dificultades de aprendizaje, de una manera propia y concreta en referencia a las materias, no se desarrolle con suficiente complejidad hasta que no se produzca el cambio de concepción necesario. Tal perspectiva debe dirigirse hacia una visión pedagógica digital otorgándole a esta un mayor equilibrio respecto a los contenidos. Sin embargo, sería en cierta medida exclusiva sino se produce una exposición en abierto (Open Access) y sobre todo si se mantienen las desigualdades pertinentes de acceso a los recursos por los más desfavorecidos. Ejemplo: Una simulación de la realidad mediante última generación interactiva que te permita interpretar una gran cantidad de contenidos y aspectos pedagógicos específicos de una unidad didáctica de historia. La aplicación de tal manifestación a todos los institutos y más aún en versión libre y de calidad en la red es un espejismo a día de hoy por la inversión que además traería consigo incentivando una brecha digital mayor. Por tanto, en este contexto actual provocado por la COVID-19, como siempre suele pasar, se prevé un efecto mayor en los estudiantes con más pobreza endémica dentro de un contexto ambiental inestable. No se puede desdeñar el papel que tomará la evolución de la web 2.0 hacia procesos más complejos, como por ejemplo la web 3.0 o semántica donde se aprecian nuevas posibilidades de interacción y de uso en la red. 


\section{Referencias}

Academia de las Artes y las Ciencias Cinematográficas de España (15/09/2020). Recuperado de: https:// www.academiadecine.com/educacion/

Acosta Barros, L. M. (2010). La enseñanza-aprendizaje de la historia en bachillerato y las TIC: la introducción de la estrategia Webquest", Proyecto Clío, 36. Recuperado de: http://clio.rediris.es/n36/didactica/ Imacosta_iehcan.pdf

Álvarez Otero, J. y Lázaro Y Torres, M. L. (2019). Las infraestructuras de datos espaciales: un reto y una oportunidad en la docencia de la Geografía. Boletín de la Asociación de Geógrafos españoles (BAGE). 82, DOI: $10.21138 /$ bage. 2787

American Psychiatric Association (2002). Manual Diagnóstico e Estatístico de Transtornos Mentais (DSM-IV-TR). Tradução de M. R. Jorge (4.a ). Porto Alegre, Brasil: ARTMED.

Anónimo (15/09/2020). Google Docs Proyecto ABP, Canvas. Recuperado de: https://docs.google.com/ drawings/d/1Lp_JeL53Lm6U0968AZlyKhJvnulzRm-8n5yBVKLEmIU/edit

Arancibia Herrera, M. M. y Badia Garganté, A. (2013). Caracterización y valoración de los usos educativos de las TIC en 10 secuencias didácticas de historia de enseñanza secundaria. Estudios pedagógicos, 39(3) (especial), 7-24. DOI: 10.4067/S0718-07052013000300002.

Arancibia Herrera, M. M. y Badia Garganté, A. (2015). Concepciones de profesores de secundaria sobre enseñar y aprender Historia con TIC. Revista Electrónica de Investigación Educativa, 17 (2), 63-75. Recuperado de: http:// www.scielo.org.mx/pdf/redie/v17n2/v17n2a5.pdf

Asociación de Geógrafos Españoles (AGE) (15/09/2020). Listado de revistas científicas. Recuperado de: https:// www.age-geografia.es/site/revistas-de-tematica-geografica-2/

Asociación de Geógrafos Españoles (AGE) (16/09/2020). Recursos didácticos. Recuperado de: https:// www.age-geografia.es/site/recursos-didacticos/

Atlassian (15/09/2020). Trello. Recuperado de: https://trello.com/es

Audacity (15/09/2020). Recuperado de: https://www.audacityteam.org/

Aula Planeta (16/09/2020). Recuperado de: https://www.aulaplaneta.com/

Automattic (15/09/2020). Wordpress. Recuperado de: https://es.wordpress.com/

Ayén, F. (16/09/20). Web del profesor Francisco. Recuperado de: https://www.profesor francisco.es/

Benejam, P. y Pagés, J. (coords.) (1997). Enseñar y aprender Ciencias Sociales, Geografía e Historia en la Educación Secundaria. Barcelona, España: Horsori, 169-174

Canva (15/09/2020). Recuperado de: https://www.canva.com/es es/

Centro Nacional de Información Geográfica (CNIG) (15/09/2020). Cartociudad. Recuperado de: http:// www.cartociudad.es/

Centro Superior de Investigaciones Científicas (CSIC) (15/09/2020). Índices CSIC. Recuperado de: https:// indices.csic.es/

Cinergix Pty. Ltd. (15/09/2020). Creatly. Recuperado de: https://creately.com/es/home/

Clarivate Analytics (15/09/2020). Web Of Science. Recuperado de: https://www.webofknowle dge.com/

ClassDojo, Inc (15/09/2020). Classdojo. Recuperado de: https://classdojo.com/es-es/

Claval, P. (2007). Épistemologie de la géographie. París, Francia: Armand Colin.

Comes, P. (1998). El espacio en la didáctica de las Ciencias Sociales. En: Trepat, C. y Comes, P., El tiempo y el espacio en la didáctica de las Ciencias Sociales (125-128). Barcelona, España: Graó.

Comisión Europea (16/09/20). eTwinning. Recuperado de: https://www.etwinning.net/es/pub/index.htm

Contreras Espinosa, R. y Luis Eguia, J. (Edts.) (2017). Experiencias de gamificación en aulas. Barcelona, España: InCom-UAB Publicacions, 15. Recuperado de: https://ddd. uab.cat/pub/ Ilibres/2018/188188/ 
ebook15.pdf

Cospaces (15/09/2020). Recuperado de: https://www.cospaces.io/edu/

Cózar Mata, J. (2009). Dificultades de aprendizaje en Historia. Psicopedagogía. Recuperado: http:// www.psicopedagogia.com/articulos/?articulo $=461$

De la Torre Cárdenas, M. A. (16/09/20). Recursos de ciencias sociales. Recuperado de: https:// flautarociera.com/ccss/?page id $=363$

Decreto 219/2011, de 28 de junio, por el que se aprueba el Plan para el Fomento de la Cultura Emprendedora en el Sistema Educativo Público de Andalucía (BOJA, núm. 137 del 14 de julio de 2011). Recuperado de: https://www.juntadeandalucia.es/boja/2011/137/1

Dep Institut (18/04/2020). Másteres oficiales de tecnología educativa. Educaweb. Recuperado de: www.educaweb.com/ masters-oficiales-de/tecnologia-educativa/

Editorial Vicens Vives (16/09/2020). Viven Vives. Recuperado de: http://www.vicensvives.com/

EDpuzzle Inc (15/09/2020). Edpuzzle flipped. Recuperado de: https://go.edpuzzle.com/flipp ed.html

Elsevier (15/09/2020). Scopus. Recuperado de: https://www.scopus.com/

Enríquez, S. C. (2012). Luego de las TIC, las TAC. Informe. Universidad Nacional de la Plata, 1-12.

Estepa Giménez, J. (2009). Aportaciones y retos de la investigación en la didáctica de las ciencias sociales. Investigación en la escuela, 69, 22-23. DOI: 10.12795/IE.2009.i69.02

Fatás Cabeza, G. (Dir.) (15/09/2020). Gran Enciclopedia de España. Recuperado de: https://gee.mienciclo.com/

FBReader.ORG Limited (15/09/2020). Fbreader Recuperado de: https://fbreader.org/

Fernández-Quero, J. L. (2020). El uso coherente de las TIC mediante el modelo TPACK aplicado a las dificultades del aprendizaje en geografía. En: G. Gómez García, M. Ramos Navas-Parejo, C. Rodríguez Jiménez y J. C. de la Cruz Campos. Teoría y práctica en investigación educativa: una perspectiva internacional (Capítulo 69, 851-863). Madrid, España: Ed. Dykinson S. L. ISBN: 978-84-1377-174-8

Fernández Verdú, C., Sospedra Roca, R., Gómez Crespo, M. A., Cano Ortiz, M., Feliu Torruella, M., Pozo Municio, J. I., Liesa Hernández, E., Sánchez Roda, D., Trepat Carbonell, C-A., Fuentes Moreno, C. y Linares Ciscar, S. (2017). Dificultades de aprendizaje: Matemáticas, Lenguaje, Ciencias Naturales y Ciencias Sociales. UOC. Recuperado de: http://bibliotecadigital. magisterio.co/libro/dificultades-de-aprendizaje-matemticas-lenguaje-ciencias-naturales-y-ciencias-sociales

Figueiredo, M., Mazera, S. M., Guillaumon Emmela, M. L. y Fernández Alba, E. (2014). Análisis de la producción científica en Brasil sobre dificultades de aprendizaje: una revisión bibliométrica. Aula abierta, (42), 36.

Fleitas, A. y Gómez, S. (2012). Una introducción a la problemática de la alfabetización cartográfica en la geografía escolar. La lectura y escritura de mapas desde las TIC/TAC. Estudios socioterritoriales. Revista de Geografía, 11 (1). Recuperado de: https://doaj.org/article/ b5b6e249082e47878860f7e742beca37

Gail Rickey, M. y Bein, F. L. (1996). Students' Learning Difficulties in Geography and Teachers' Interventions: Teaching Cases from K-12 Classrooms. Journal of Geography. 95, 3, 118-125. DOI: $10.1080 / 00221349608978703$

García de la vega, A. (2007). Las dificultades de aprendizaje en el área de las Ciencias Sociales. Boletín Colegio de Doctores y Licenciados de Madrid 184, 23-24. Recuperado de: https://repositorio.uam.es/handle/ $\underline{10486 / 666619}$

García Perales, R. y García Perales, R. (2003). Dificultades de aprendizaje en ciencias sociales: "lectura e interpretación de mapas y planos" Ensayos: Revista de la Facultad de Educación de Albacete, 73. Recuperado de: https://dialnet. unirioja.es/descarga/articulo/ 1032303.pdf

García Ruiz, A. L. y Jiménez, J. A. (2006). Los Principios Científico- Didácticos (P.C.D). Nuevo modelo para la enseñanza de la Geografía y de la Historia. Granada. Editorial Universidad de Granada, 494.

Genially (15/09/2020). Recuperado de: https://www.genial.ly/es 
Gómez Trigueros, I. (2016). La didáctica de la Geografía y las TIC: nuevas metodologías de enseñanza y aprendizaje. En (Coords. J. D. Álvarez Teruel, Grau Company, S., M. T. Tortosa Ybañez): Innovaciones metodológicas en docencia universitaria: resultados de investigación (pp. 819-849). Alicante. Universidad de Alicante.

Google (15/09/2020). Google Arts and Culture. Recuperado de: https://artsandculture.google.co m/

Google (15/09/2020). ARCore. Recuperado de: https://create.withgoogle.com/intl/es-mx/platforms/more-adformats/arcore

Google (15/09/2020). Google Classroom. Recuperado de: https://classroom.google.com/

Google (15/09/2020). Google Drive. Recuperado de: https://www.google.es/drive/apps.html

Google (15/09/2020). Google Earth. Recuperado de: https://www.google.com/intl/es/earth/

Google (15/09/2020). Google Maps. Recuperado de: https://www.google.es/maps/?hl=es

Google (15/09/2020). Google Scholar. Recuperado de: https://scholar.google.es/

Google (15/09/2020). Google Sites. Recuperado de: https://sites.google.com/?hl=es

Google (15/09/2020). YouTube. Recuperado de: https://www.youtube.com/?hl=es\&gl=ES

Gran Enciclopedia Iberoamericana (15/09/2020). Recuperado de: https://ibero.mienciclo.com/

Graves, N. J. (1985). La enseñanza de la geografía. Madrid, España: Visor.

Grupo Anaya (16/09/2020). Anaya. Recuperado de: https://www.anayaeducacion.es/

Grupo Esri (15/09/2020). ArcGIS Online. Recuperado de: https://colegios.esri.es/portal-recursos/

Gurevich, R. (1998). Conceptos y problemas en geografía herramientas básicas para una propuesta educativa. En S. Alderoqui, B. Aisenberg, (Coord), Didáctica de las ciencias sociales II: teorías con prácticas (160).

Helpdesk Theme (15/09/2020). Tinytap. Recuperado de: https://www.tinytap.it/

Hernández Cardona, F. X. (2011). La iconografia en la didáctica de las ciencias sociales. Íber. Didáctica de las Ciencias Sociales, Geografía e Historia, 68, 7-16.

Historia y Arqueología (16/09/2020). Recuperado de: http://www.historiayarqueologia.com/

Idoceo Labs (15/09/2020). Idoceo. Recuperado de: https://www.idoceo.es/

Instituto Geográfico Nacional (16/09/2020). Glosario de términos geográficos para las pruebas de acceso a la universidad. https://www.ign.es/web/ign/portal/recursos-educativos/glosario-IGN-AGE

Instituto Geográfico Nacional (16/09/2020). Recuperado de: https://www.ign.es/

Instituto Nacional de Tecnologías Educativas y de Formación del Profesorado (INTEF). (16/09/2020). Recuperado de: https://intef.es/

INTEF (16/09/20). Aula Virtual. Recuperado de: http://formacion.intef.es/tutorizados/

INTEF (16/09/20). Banco de imágenes y sonidos. Recuperado de: http://recursostic.educacion.es/ bancoimagenes/web/

INTEF (16/09/20). Banco de rúbricas. Recuperado de: https://cedec.intef.es/banco-de-rubricas-y-otrosdocumentos/

INTEF (16/09/20). Experiencias Educativas Innovadoras. Recuperado de: https://intef.es/recursos-educativos/ experiencias-educativas-inspiradoras/

INTEF (16/09/20). La aventura de aprender. Recuperado de: https://intef.es/recursos-educativos/la-aventurade-aprender/

INTEF (16/09/20). Observatorio de Tecnología Educativa. Recuperado de: https://intef.es/ tecnologiaeducativa/observatorio-de-tecnologia-educativa/

INTEF (16/09/20). Procomún. Red de Recursos Educativos en Abierto. Recuperado de: http:// procomun.educalab.es/es 
INTEF (16/09/20). Proyecto Edad. Recuperado de: http://recursostic.educacion.es/secundaria/ edad/

INTEF (16/09/20). Proyecto EDIA (eXeLearning). Recuperado de: https://cedec.intef.es/recursos/; https:// exelearning.net/

INTEF (16/09/20). Simuladores de Formación Profesional. Recuperado de: http://recursostic.educa cion.es/ fprofesional/simuladores/web/

INTEF (16/09/20). Todo FP. Recuperado de: http://www.todofp.es/inicio.html

INTEF (2017). Una breve historia de las TIC Educativas en España. Ministerio de Educación, Cultura y Deporte. España, 1-11. Recuperado de: https://intef.es/wp-content/uploads/2017/05/ Breve historia_TIC_Educativas_Espana.pdf

InterActiveCorp (15/09/2020). Vimeo. Recuperado de: https://vimeo.com/es

Irigaray, M. y Luna, M. (2014). La enseñanza de la Historia a través de videojuegos de estrategia: Dos experiencias áulicas en la escuela secundaria. Clío \& Asociados (19), 411-437.

Jiménez-Palacios, R. y Cuenca López, J. M. (2015). El uso didáctico de los videojuegos. Concepciones e ideas de futuros docentes de ciencias sociales. CLIO. History and History teaching, 41.

Junta de Andalucía (15/09/2020). Red Información Ambiental de Andalucía (REDIAM). Recuperado de: http:// www.juntadeandalucia.es/medioambiente/site/rediam

Junta de Andalucía (16/09/20). Agrega. Recuperado de: http://agrega.juntadeandalucia.es/

Junta de Andalucía (16/09/20). Blog Averroes. Recuperado de: https://blogsaverroes.junta deandalucia.es/ eaprendizaje/

Kahoot (15/09/2020). Recuperado de: https://kahoot.com/

Kitson, A., Steward, S. y Husbands, C. (2015). Didáctica de la historia en Secundaria Obligatoria y Bachillerato: Comprender el pasado. Las Rozas, Madrid. Morata. 73

Ley 17/2007, de 10 de diciembre, de Educación de Andalucía (BOJA, núm. 252 del 26 de diciembre de 2007). Recuperado de: https://www.juntadeandalucia.es/boja/2007/252/1

Liarte, R. (16/09/20). Blog Lecciones de historia. Recuperado de: https://leccionesdehistoria.com/

Liarte, R. (16/09/20). Web Rosa Liarte. Recuperado de: https://rosaliarte.com/

Liceras, A. (1997). Las dificultades en el aprendizaje de las Ciencias Sociales. Una perspectiva psicodidáctica. Grupo Editorial Universitario, 113,116.

Liceras, A. (2000). Tratamiento de las dificultades de aprendizaje en Ciencias Sociales. Grupo Editorial Universitario. Granada.

Liceras, A. y Romero, G. (Coords.) (2016). Didáctica de las Ciencias Sociales. Fundamentos, contextos y propuestas. Madrid, España: Pirámide.

Luis de la Torre, J. (2005). Las nuevas tecnologías en las clases de ciencias sociales del siglo XXI. Iber: Didáctica de las ciencias sociales, geografía e historia. 48, 97-114. Recuperado de: http:// www.quadernsdigitals.net/datosweb/hemeroteca/r1/nr609/a8300/8300.pdf

Marrero Urbín, D. (2012). Factores de la integración de las TIC en el currículo de historia. El modelo de enseñanza practicado como llave del fracaso y del éxito. Clio \& Asociados (16). Recuperado de: http:// www.clioyasociados.fahce.unlp.edu.ar

Mayer, R., Howarth, J., Kaplan, M. y Hanna, S. (2017). Applying the segmenting principle to online geography slideshow lessons. Educational Technology Research and Development, (66). 563-577. DOI: 66. $10.1007 / \mathrm{s} 11423-017-9554-\mathrm{x}$

Microsoft (15/09/2020). Skype. Recuperado de: https://www.skype.com/es/

Ministerio de Cultura y Deporte (15/09/2020). Censo-guía de Archivos de España e Iberoamércana (15/09/2020). Recuperado de: http://censoarchivos.mcu.es/ 
Ministerio de Educación y Formación Profesional (16/09/20). Aula Mentor. Recuperado de: http:// www.aulamentor.es/

Ministerio de Educación y Formación Profesional (16/09/2020). Centro para la Innovación y Desarrollo de la Educación a Distancia. Recuperado de: http://recursostic.educa cion.es/ secundaria/edad/

Ministerio de Transportes, Movilidad y Agenda Urbana (15/09/2020). Instituto Geográfico Nacional (IGN). Recuperado de: https://www.ign.es/

Mojang Synergies AB (15/09/2020). Minecraft Education Edition. Recuperado de: https://educa tion.minecraft.net/

Moodle TM (15/09/2020). Moodle. Recuperado de: https://moodle.org/?lang=es

Morales Rodríguez, E. M., Navarro Valverde, F. A. y Valiñas López, F. M (2018). Complementos a la formación en las ciencias sociales. Departamentos de Geografía Humana, Historia Antigua e Historia del Arte. Universidad de Granada.

Muñoz de la Peña, F. (15/09/2020). Aula 21. Recuperado de: https://aula21.net/cazas/caza.htm

Murillo, F. J. y Martínez-Garrido, C. (2018). Magnitud de la Segregación escolar por nivel socioeconómico en España y sus Comunidades Autónomas y comparación con los países de la Unión Europea. Revista de Sociología de la Educación (RASE), 11, 1. DOI: 10.7203/ RASE.11.1.10129

Museo del Prado (15/09/2020). Recuperado de: https://www.museodelprado.es/

Museo Metropolitano de Arte de Nueva York (16/09/20). The Met 150. Recuperado de: https:// www.metmuseum.org/art/metpublications/titles-with-full-text-online?searchtype $=\mathrm{F}$

Naik, D. C y Teelock, V. (2006). Mejorar la enseñanza y el aprendizaje de la historia y la geografía mediante la tecnología de la información y las comunicaciones: una experiencia de Mauricio. Investigación y desarrollo de tecnología educativa 54 (4), 422 - 434. DOI: 10.1007/s11423-006-9608-y

National Geographic (15/09/2020). National Geographic Map Marker Recuperado de: https:// mapmaker.nationalgeographic.org/

OBS Studio Contributors (15/09/2020). OBS Studio. Recuperado de: https://obspro ject.com/es

Padilla Portillo, F. E. y Gómez Zermeño, M. G. (2014). Incorporación de las Tecnologías de Información y Comunicación para la enseñanza de las Ciencias Sociales. ${ }^{3}$ Ciencias. 3TIC, 3-4, 197 - 211. Recuperado de: https://www.researchgate.net/publication/270883111_Incor poracion de las Tecnologias de Informacion_y_Comunicacion_para_la_ensenanza_de_las_Ciencias_Sociales

Palomo Molano, J. A. (2010). La Web 2.0: una aplicación didáctica para las ciencias sociales. En: J. Soto Vázquez, A. H Hernández Carretero, A. Pantoja Chaves (Edits.), La didáctica de las ciencias sociales y las competencias básicas. Tejuelo, España. Junta de Extremadura, no 4.

Parlamento europeo (2000). I. Empleo, reforma económica y cohesión social. Un objetivo estratégico para la próxima década. En: conclusiones de la presidencia. Recuperado de: https://www.europarl.europa.eu/ summits/lis 1 es.htm

PlanetaDocumental (16/09/2020). Recuperado de: https://www.planetadocumental.com/

Pluckrose, H. (1993). Enseñanza y aprendizaje de la historia. Madrid, España: Morata, 33, 65.

Pozo, J. I., Asensio, M. y Carretero, M. (1986). ¿Por qué prospera un país? Un análisis cognitivo de las explicaciones en historia. Infancia y Aprendizaje, (34), 23, 25, 27, 40.

Prats, J. (2017). Retos y dificultades para la enseñanza de la historia. Histodidáctica. 16. Recuperado de: http://www.ub.edu/histodidactica/images/documentos/pdf/Dificultades \%20 y\%20retos\%20para\%20ensear\%20historia.pdf

Prezzi (15/09/2020). Recuperado de: https://prezi.com/es/

Pyra Labs Google (15/09/2020). Blogger. Recuperado de: https://www.blogger.com/

Quizlet LLC (15/09/2020). Quizlet. Recuperado de: https://quizlet.com/es 
Radio Televisión Española (RTVE) (16/09/2020). Recuperado de: https://www.rtve.es/

Real Academia de Historia (15/09/2020). Diccionario de la Real Academia de Historia. Recuperado de: http:// dbe.rah.es/

Real Decreto 1105/2014, de 26 de diciembre, por el que se establece el currículo básico de la Educación Secundaria Obligatoria y del Bachillerato (BOE núm. 3, 3 de enero de 2015, 2015-37). Recuperado de: https://www.boe.es/boe/dias/2015/01/03/pdfs/BOE-A-2015-37.pdf

Rivero, M. P. (2011). La arqueología virtual como frente de materiales para el aula. Iconografía didáctica. Íber. Didáctica de las Ciencias Sociales, Geografía e Historia, (68), 17-24.

Royo Climent, J. (2017). El vídeo participatiu per estudiar geografia a l'ensenyament secundari. Documents d'Anàlisi Geogràfica, (63) 3, 649-657. DOI: 10.5565/rev/dag.497

Salazar Sotelo, J. (2001). Problemas de enseñanza y aprendizaje en la historia. ¿...Y los maestros que enseñamos por la historia?. México. 10. Recuperado de: http://xplora.ajusco.upn.mx:8080/xplora-pdf/ Julia\%20Salazar \%20Sote lo.pdf

Sánchez Cabielles, P. (2014). TIC y didáctica de la geografía: el papel del SIG en la Educación Secundaria (TFM). Universidad de Cantabria. Santander.

Sandford, H. (1972). Perceptual Problem. En Graves (edit.) New Movements in the Study and Teaching of Geography, (83-92). Melbourne, Australia.

Santiago Rivera, J. A. (2006). Otras formas para enseñar y aprender geografía en la práctica escolar. Revista pedagógica, (27) 80 . Recuperado de: http://ve.scielo.org/scielo.php? script $=$ sci arttext\&pid $=$ S0798-97922006000300005

Santillana (16/09/2020). Recuperado de: https://santillana.es/

Screencast-o-matic (15/09/2020). Recuperado de: https://screencast-o-matic.com/

Segrelles Serrano, J. A. y Gómez Trigueros, I. M. (2016). Nuevas metodologías activas de EnseñanzaAprendizaje: Didáctica de la Geografía y la Literatura a través de la TIC Google EarthTM. Instituto de Ciencias de la Educación. Conferencia: Investigación e Innovación Educativa en Docencia Universitaria: retos, propuestas y acciones. Universidad de Alicante, España.

Seva Cañizares, F. (2015). Las TIC en la enseñanza de la Geografía y la Historia: Concepciones de los alumnos (Tesis Doctoral). Universidad de Alicante. Alicante, España.

Smithwick, E., Baxter, E., Kim, K., Edel-Malizia, S., Rocco, S. y Blackstock, D. (2018). Interactive Videos Enhance Learning about Socio-Ecological Systems. Journal of Geography, 117 (1), 40-49. DOI: 10.1080/0022 1341.2017.1374433

Sobrino López, D. (2011). Manifestaciones artísticas en la villa de Coca. Curso de Historia de Segovia. Real Academia de Historia y Arte de San Quirce. XXXII

Tabor, L. K. y Harrington, J. A. (2014). Lessons learned from professional development workshops on using GIS to teach geography and history in the K-12 classroom. Geography Teacher, 11(2), 47-54.

The Apache Software Foundation (15/09/2020). OpenOffice Writer. Recuperado de: https:// www.openoffice.org/es/

Timetoast timelines (15/09/2020). Timeline. Recuperado de: https://www.timetoast.com/time lines/dipityonline-timeline

Trimble (15/09/2020). 3D Wharehouse. Recuperado de: https://3dwarehouse.sketchup.com/ ?hl=es

Unión Europea (15/09/2020). Europeana. Recuperado de: https://www.europeana.eu/

Unión Europea (16/09/20). Rincón del profesor. Recuperado de: https://europa.eu/learning-corner/\#item_1

UNIR (2019). Competencias digitales para docentes y la Web 2.0. Recursos educativos. Cursos universitarios. Universidad de La Rioja, España.

Universidad de La Rioja (15/09/2020). Dialnet. Recuperado de: https://dialnet.unirioja.es/ 
Universidad de Oxford (15/09/2020). Oxford Art Online. Recuperado de: https://www.oxfordart online.com/ Universidad de Oxford (15/09/2020). Oxford Reference. Recuperado de: https://www.oxfordre ference.com/

Universitat de Barcelona (Juaquín Prats) (16/09/2020). Histodidáctica Recuperado de: http://www.ub.edu/ histodidactica/

Valls, R. y Facal, R. (2012). ¿Un nuevo paradigma para la enseñanza de la historia? los problemas reales y las polémicas interesadas al respecto en España y en el contexto del mundo occidental. Histodidáctica. Recuperado de: http://www.ub.edu/histodidactica/index.php? option =com_content\&view =article\&id=152: un-nuevo-paradigma-para-la-ensenanza-de-la-historia-losproblemas-reales-y-las-polemicas-interesadas-al-respecto-en-espana-y-en-el-contexto-del-mundooccidental\&catid=36: posterior-a-2010\&Itemid $=104$

Vera Muñoz, M. I. y Pérez I Pérez, D. (2004). Formación de la ciudadanía: Las TICs y los nuevos problemas. XV Simposio Internacional de Didáctica de las Ciencias Sociales Asociación Universitaria de Profesores de Didáctica de las Ciencias Sociales. Recuperado de: http:// www.cervantesvirtual.com/ nd/ark:/59851/ bmccn7fo

Weebly (15/09/2020). Recuperado de: https://www.weebly.com/es

Wix.com, Inc (15/09/2020). WIX. Recuperado de: https://es.wix.com/

Wondershare (15/09/2020). Filmora Recuperado de: https://filmora.wondershare.com/es/

Zoom Video Communications, Inc. (15/09/2020). Zoom. Recuperado de: https://zoom.us/ 